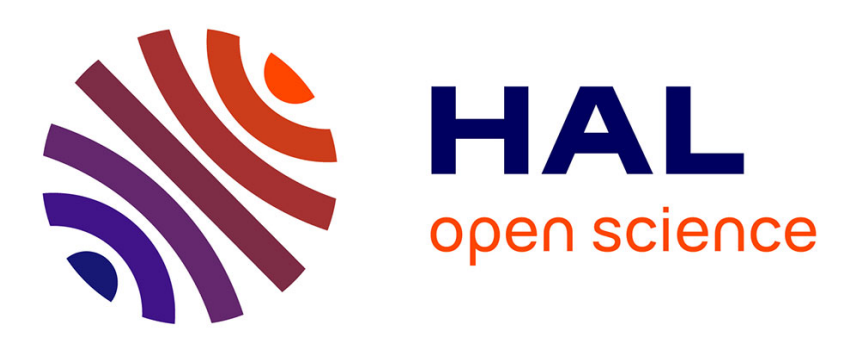

\title{
Improved subset simulation for the SLS analysis of two neighboring strip footings resting on a spatially random soil
}

\author{
Ashraf Abd El-Modby Soliman Ahmed, Abdul-Hamid Soubra
}

\section{- To cite this version:}

Ashraf Abd El-Modby Soliman Ahmed, Abdul-Hamid Soubra. Improved subset simulation for the SLS analysis of two neighboring strip footings resting on a spatially random soil. Geo-congress 2012: State of the Art and Practice in Geotechnical Engineering, ASCE, 2012, Oakland, United States. pp.2826-2835, 10.1061/9780784412121.289 . hal-01008298

\section{HAL Id: hal-01008298 \\ https://hal.science/hal-01008298}

Submitted on 8 Jun 2018

HAL is a multi-disciplinary open access archive for the deposit and dissemination of scientific research documents, whether they are published or not. The documents may come from teaching and research institutions in France or abroad, or from public or private research centers.
L'archive ouverte pluridisciplinaire HAL, est destinée au dépôt et à la diffusion de documents scientifiques de niveau recherche, publiés ou non, émanant des établissements d'enseignement et de recherche français ou étrangers, des laboratoires publics ou privés. 


\title{
Improved Subset Simulation for the SLS Analysis of Two Neighboring Strip Footings Resting on a Spatially Random Soil
}

\author{
Ashraf Ahmed ${ }^{1}$ and Abdul-Hamid Soubra ${ }^{2}$ \\ ${ }^{1}$ University of Nantes, Department of Civil Engineering, Bd. de l'université, BP 152, \\ 44603 Saint-Nazaire cedex, France. PH: (0033)240905106; FAX: (0033)240905109; \\ email: Ashraf.ahmed@univ-nantes.fr, \\ ${ }^{2}$ University of Nantes, Department of Civil Engineering, Bd. de l'université, BP 152, \\ 44603 Saint-Nazaire cedex, France. PH: (0033)240905108; FAX: (0033)240905109; \\ email: Abed.Soubra@univ-nantes.fr,
}

\begin{abstract}
The computation of the failure probability of geotechnical structures with the consideration of the soil spatial variability is generally performed using Monte Carlo Simulation (MCS) methodology. This method is very time-consuming when computing a small failure probability. As an alternative, Subset Simulation (SS) approach was proposed by $\mathrm{Au}$ and Beck (2001) to efficiently calculate the small failure probability. In the present paper, a more efficient approach called the improved Subset Simulation (iSS) is employed. In this approach the efficiency of SS is increased by replacing the first step of SS by a conditional simulation in which the realizations are generated outside a hypersphere of a given radius. This approach is illustrated here through the probabilistic analysis at the serviceability limit state (SLS) of two neighboring strip footings that rest on a soil with spatially varying Young's modulus. A comparison between SS and iSS approaches has shown that a considerable reduction in the number of realizations can be achieved when using the iSS approach.
\end{abstract}

KEY WORDS: subset simulation; improved subset simulation; conditional simulation; strip footings; differential settlement.

\section{INTRODUCTION}

The classical Monte Carlo Simulation (MCS) methodology is generally used to calculate the failure probability of problems involving a spatial variability of the soil properties. This method is very time-consuming when computing a small failure probability. This is due to the large number of realizations required in such a case. As alternative to MCS methodology, the Subset Simulation (SS) approach was proposed by Au and Beck (2001) to calculate the small failure probability. The first step of SS method is to generate a given number of realizations of the uncertain parameters using the classical MCS technique. The second step is to use the Metropolis-Hastings $(\mathrm{M}-\mathrm{H})$ algorithm to generate realizations in the direction of the limit state surface (i.e. $\mathrm{G}=0$ ). This step is repeated until reaching the limit state surface. It should be emphasized here that in case of a small failure probability, SS requires the repetition of the second step many times to reach the limit state surface. This leads to a high 
computational time. To reduce the computational cost of SS, Defaux et al. (2010) proposed an improved subset simulation (iSS) method. In this method, the efficiency of SS is increased by replacing the first step by a conditional simulation. In other words, instead of generating realizations directly around the origin by the classical MCS, the realizations are generated outside a hypersphere of a given radius. Consequently, the number of realizations required to reach the limit state surface is significantly reduced. Notice that Defaux et al. (2010) have employed the iSS to calculate the failure probability in the case where the uncertain parameters are modeled by random variables. In the present paper, the iSS is employed in the case where the uncertain parameters are modeled by random fields. This method is illustrated through the computation of the probability $\left(\mathrm{P}_{\mathrm{e}}\right)$ of exceeding a tolerable differential settlement between two neighboring strip footings resting on a soil with a spatially varying Young's modulus. The footings are subjected to central vertical loads with equal magnitude. The random field is discretized using the KarhunenLoeve (K-L) expansion. The differential settlement between the two footings was used to represent the system response. The deterministic model used to compute the system response is based on numerical simulations using the commercial software FLAC.

\section{REVIEW OF THE CLASSICAL SUBSET SIMULATION (SS) APPROACH}

Subset simulation was proposed by Au and Beck (2001) to compute the small failure probabilities. The basic idea of the SS approach is that the small failure probability can be expressed as a product of larger conditional failure probabilities. Consider a failure region $F$ defined by the condition $G<0$ where $G$ is the performance function and let $\left(\mathrm{s}_{1}, \ldots, \mathrm{s}_{\mathrm{k}}, \ldots, \mathrm{s}_{\mathrm{Nt}}\right)$ be $\mathrm{N}_{\mathrm{t}}$ samples located in the space of the uncertain variables where $\mathrm{s}$ represents a vector of random variables. It is possible to define a sequence of nested failure regions $\mathrm{F}_{1}, \ldots, \mathrm{F}_{\mathrm{j}}, \ldots, \mathrm{F}_{\mathrm{m}}$ of decreasing size where $\mathrm{F}_{1} \supset \ldots \supset \mathrm{F}_{\mathrm{j}} \supset \ldots \supset \mathrm{F}_{\mathrm{m}}=\mathrm{F}$ as shown in figure 1. An intermediate failure region $\mathrm{F}_{\mathrm{j}}$ can be

defined by $G_{j}<C_{j}$ where $C_{j}>0$. Thus, there is a decreasing sequence of positive numbers $\mathrm{C}_{1}, \ldots, \mathrm{C}_{\mathrm{j}}, \ldots, \mathrm{C}_{\mathrm{m}}$ corresponding respectively to $\mathrm{F}_{1}, \ldots, \mathrm{F}_{\mathrm{j}}, \ldots, \mathrm{F}_{\mathrm{m}}$ where $\mathrm{C}_{1}>\ldots>\mathrm{C}_{\mathrm{j}}>\ldots>\mathrm{C}_{\mathrm{m}}=0$. The $\mathrm{N}_{\mathrm{t}}$ samples $\left(\mathrm{s}_{1}, \ldots, \mathrm{s}_{\mathrm{k}}, \ldots, \mathrm{s}_{\mathrm{Nt}}\right)$ will be divided into groups of equal number $\mathrm{N}_{\mathrm{s}}$ of samples $\left(\mathrm{s}_{1}, \ldots, \mathrm{s}_{\mathrm{k}}, \ldots, \mathrm{s}_{\mathrm{Ns}}\right)$. Thus, $\mathrm{N}_{\mathrm{t}}=\mathrm{mxN}_{\mathrm{s}}$ where $\mathrm{m}$ is the number of failure regions. The $\mathrm{N}_{\mathrm{s}}$ samples of the first group are generated by MCS methodology according to a target PDF $\left(\mathrm{P}_{\mathrm{t}}\right)$. The corresponding failure probability $\mathrm{P}\left(\mathrm{F}_{1}\right)$ is calculated as follows:

$\mathrm{P}\left(\mathrm{F}_{1}\right)=\frac{1}{\mathrm{~N}_{\mathrm{s}}} \sum_{\mathrm{k}=1}^{\mathrm{Ns}} \mathrm{I}_{\mathrm{F}_{1}}\left(\mathrm{~s}_{\mathrm{k}}\right)$

where $I_{F_{1}}=1$ if $s \in F_{1}$ and $I_{F_{1}}=0$ otherwise. On the other hand, the samples of the remaining groups are generated using Metropolis- $\underline{\text { Hastings }}$ algorithm according to a proposal PDF $\left(\mathrm{P}_{\mathrm{p}}\right)$. The failure probability corresponding to an intermediate failure region $F_{j}$ where $j \neq 1$ is calculated as follows:

$\mathrm{P}\left(\mathrm{F}_{\mathrm{j}} \mid \mathrm{F}_{\mathrm{j}-1}\right)=\frac{1}{\mathrm{~N}_{\mathrm{s}}} \sum_{\mathrm{k}=1}^{\mathrm{Ns}} \mathrm{I}_{\mathrm{F}_{\mathrm{j}}}\left(\mathrm{s}_{\mathrm{k}}\right)$ 
$\mathrm{I}_{\mathrm{F}_{\mathrm{j}}}=1$ if $\mathrm{s} \in \mathrm{F}_{\mathrm{j}}$ and $\mathrm{I}_{\mathrm{F}_{\mathrm{j}}}=0$ otherwise. The failure probability $\mathrm{P}(\mathrm{F})$ of the failure region F can be calculated from the sequence of conditional failure probabilities as follows: $P(F)=P\left(F_{1}\right) x \prod_{j=2}^{m} P\left(F_{j} \mid F_{j-1}\right)$

\section{IMPROVED SUBSET SIMULATION (iSS) APPROACH}

As mentioned previously, the basic idea of iSS is to replace the first step of SS by a conditional simulation (Defaux et al. 2010) in which, the realizations are generated outside a hypersphere of a given radius $\beta$ (figure 2 ).

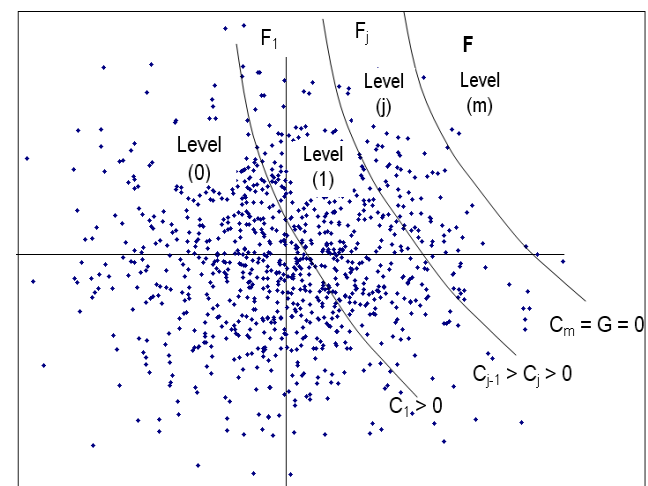

Figure 1. Nested failure domain

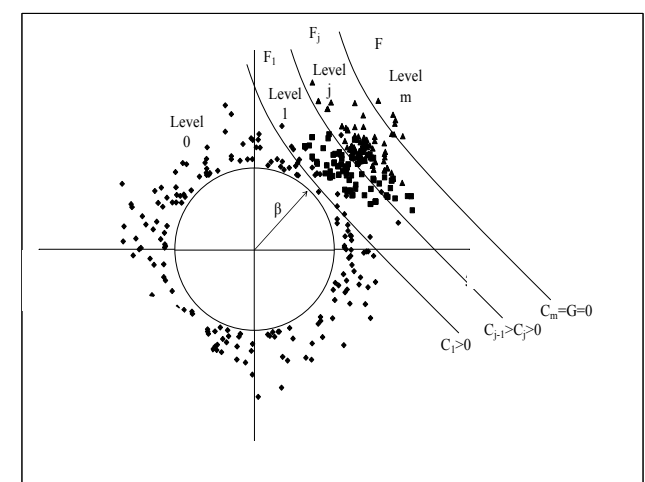

Figure 2. Samples generation outside a hypersphere of radius $\beta$

Based on this conditional simulation, the failure probability $\mathrm{P}\left(\mathrm{F}_{1}\right)$ corresponding to the first level of subset simulation (i.e. level 0) is calculated as follows (Defaux et al. 2010):

$\mathrm{P}\left(\mathrm{F}_{1}\right)=\left(1-\chi_{\mathrm{M}}\left(\beta^{2}\right)\right) \frac{1}{\mathrm{~N}_{\mathrm{s}}} \sum_{\mathrm{k}=1}^{\mathrm{Ns}} \mathrm{I}_{\mathrm{F}_{1}}\left(\mathrm{~s}_{\mathrm{k}}\right)$

where $\chi_{\mathrm{M}}$ is the chi-square distribution with $\mathrm{M}$ degrees of freedom and $\mathrm{I}_{\mathrm{F}_{1}}=1$ if $\mathrm{s} \in \mathrm{F}_{1}$ and $\mathrm{I}_{\mathrm{F}_{1}}=0$ otherwise. The advantage of using the conditional simulation is to generate realizations in the proximity of the limit state surface leading to a reduction in the number of realizations required to reach this surface. Notice finally that the realizations of the remaining levels (i.e. levels 1 to $\mathrm{m}-1$ ) are generated using Metropolis-Hastings algorithm. The failure probability of a given level $\mathrm{j}$ where $\mathrm{j} \neq 1$ is calculated using Eq. (2) and the final failure probability $\mathrm{P}(\mathrm{F})$ is calculated using Eq. (3).

\section{IMPLEMENTATION OF ISS IN THE CASE OF RANDOM FIELDS}

As mentioned before, this paper aims at employing the iSS approach for the computation of the failure probability in the case of a spatially varying soil property. To achieve this purpose, a link between SS and K-L expansion is performed. For a Gaussian random field $\mathrm{E}(\mathrm{X}, \theta)$, where $\mathrm{X}$ denotes the spatial coordinates and $\theta$ 
indicates the random nature of this random field, the random field can be approximated by the K-L expansion as follows (Spanos and Ghanem 1989):

$\mathrm{E}(\mathrm{X}, \theta) \approx \mu+\sum_{\mathrm{i}=1}^{\mathrm{M}} \sqrt{\lambda_{\mathrm{i}}} \phi_{\mathrm{i}}(\mathrm{X}) \xi_{\mathrm{i}}(\theta)$

where $\mu$ is the mean of the random field, $M$ is the size of the series expansion, $\lambda_{\mathrm{i}}$ and $\phi_{\mathrm{i}}$ are the eigenvalues and eigenfunctions of the covariance function $\mathrm{C}\left(\mathrm{X}_{1}, \mathrm{X}_{2}\right)$, and $\xi_{\mathrm{i}}(\theta)$ is a vector of standard uncorrelated random variables. In the present paper, the random field $\mathrm{E}$ was assumed to follow a log-normal probability density function so that $\ln (\mathrm{E})$ is a normal random field with mean value $\mu_{\ln }$ and standard deviation $\sigma_{\ln }$. For a lognormal random field, the K-L expansion given in Eq. (5) becomes (Cho and Park 2010):

$\mathrm{E}(\mathrm{X}, \theta) \approx \exp \left\lfloor\mu_{\mathrm{ln}}+\sum_{\mathrm{i}=1}^{\mathrm{M}} \sqrt{\lambda_{\mathrm{i}}} \phi_{\mathrm{i}}(\mathrm{X}) \xi_{\mathrm{i}}(\theta)\right\rfloor$

On the other hand, the random field was assumed to follow an exponential covariance function as follows:

$\mathrm{C}\left[\left(\mathrm{x}_{1}, \mathrm{y}_{1}\right),\left(\mathrm{x}_{2}, \mathrm{y}_{2}\right)\right]=\sigma_{\ln }^{2} \exp \left(-\frac{\left|\mathrm{x}_{1}-\mathrm{x}_{2}\right|}{1_{\ln \mathrm{x}}}-\frac{\left|\mathrm{y}_{1}-\mathrm{y}_{2}\right|}{1_{\ln \mathrm{y}}}\right)$

where $\left(\mathrm{x}_{1}, \mathrm{y}_{1}\right)$ and $\left(\mathrm{x}_{2}, \mathrm{y}_{2}\right)$ are the coordinates of two arbitrary points in the domain over which the random field is defined and $l_{\ln } \mathrm{x}$ and $l_{\ln } \mathrm{y}$ are respectively the horizontal and vertical lengths over which the values of $\ln (\mathrm{E})$ are highly correlated. Notice that in the case of an exponential covariance function, the eigenvalues and eigenfunctions are given analytically. Their solutions are presented in Spanos and Ghanem (1989).

Notice that the basic idea of the link between SS and K-L expansion was given in Ahmed and Soubra (2011) and is briefly presented herein in the case of iSS approach applied to a random field problem. This link is performed through the standard normal random variables $\left\{\xi_{\mathrm{i}}\right\}_{\mathrm{i}=1, \ldots, \mathrm{M}}$ appearing in Eq. (6) as follows: for a given random field realization discretized by K-L expansion, the system response is calculated in two steps. The fist step is to substitute the vector $\left\{\xi_{i}\right\}_{i=1, \ldots, M}$ of this realization in Eq. (6) to calculate the value of the random field at each point in the domain according to its coordinates. The second step is to use the deterministic model to calculate the corresponding system response. The algorithm of iSS proposed in this paper for the case of a spatially varying soil property can thus be described as follows:

1. Prescribe a radius $\beta$ for the hypersphere and generate a vector of standard normal random variables $\left\{\xi_{1}, \ldots, \xi_{\mathrm{i}}, \ldots, \xi_{\mathrm{M}}\right\}$ by MCS methodology. This vector must realize that its norm is larger than the prescribed radius $\beta$.

2. Substitute the vector $\left\{\xi_{1}, \ldots, \xi_{\mathrm{i}}, \ldots, \xi_{\mathrm{M}}\right\}$ in the K-L expansion (Eq. 6) to obtain the first realization of the random field. Then, use the deterministic model to calculate the corresponding system response.

3. Repeat steps 1 and 2 until obtaining a prescribed number $\mathrm{N}_{\mathrm{s}}$ of realizations and their corresponding system response values. Then, evaluate the corresponding 
values of the performance function to obtain the vector $\mathrm{G}_{0}=\left\{\mathrm{G}_{0}^{1}, \ldots, \mathrm{G}_{0}^{\mathrm{k}}, \ldots, \mathrm{G}_{0}^{\mathrm{Ns}}\right\}$. Notice that the subscript ' 0 ' refers to the first level (level 0 ).

4. Prescribe a constant intermediate failure probability $\mathrm{P}\left(\mathrm{F}_{\mathrm{j}}\right)$ for all the failure regions $F_{j}$ and evaluate the first failure threshold $C_{1}$ which corresponds to the failure region $\mathrm{F}_{1}$ where $\mathrm{C}_{1}$ is equal to the $\left[\left(\mathrm{N}_{\mathrm{s}} \mathrm{xP}\left(\mathrm{F}_{\mathrm{j}}\right)\right)+1\right]^{\text {th }}$ value in the increasing list of elements of the vector $\mathrm{G}_{0}$. Thus, among the $\mathrm{N}_{\mathrm{s}}$ realizations, there are $\left[\mathrm{N}_{\mathrm{s}} \mathrm{xP}\left(\mathrm{F}_{\mathrm{j}}\right)\right]$ ones whose values of the performance function are less than $\mathrm{C}_{1}$ (i.e. they are located in the region $\left.\mathrm{F}_{1}\right)$. The failure probability $\mathrm{P}\left(\mathrm{F}_{1}\right)$ is then calculated by Eq. (4)

5. The vectors of $\left\{\xi_{1}, \ldots, \xi_{\mathrm{i}}, \ldots, \xi_{\mathrm{M}}\right\}$ corresponding to the realizations that are located in the region $F_{1}$ (from step 4) are used as 'mother vectors' to generate additional $\left[\left(1-\mathrm{P}\left(\mathrm{F}_{\mathrm{j}}\right)\right) \mathrm{N}_{\mathrm{s}}\right]$ vectors of $\left\{\xi_{1}, \ldots, \xi_{\mathrm{i}}, \ldots, \xi_{\mathrm{M}}\right\}$ using Metropolis-Hastings algorithm. These new vectors are substituted in Eq. (6) to obtain the random field realizations of level 1 . Then, the values of the performance function corresponding to these realizations should be calculated and gathered in an increasing order in the vector of performance functions $\mathrm{G}_{1}=\left\{\mathrm{G}_{1}^{1}, \ldots, \mathrm{G}_{1}^{\mathrm{k}}, \ldots, \mathrm{G}_{1}^{\mathrm{Ns}}\right\}$.

6. Evaluate the second failure threshold $\mathrm{C}_{2}$ as the $\left[\left(\mathrm{N}_{\mathrm{s}} \mathrm{xP}\left(\mathrm{F}_{\mathrm{j}}\right)\right)+1\right]^{\text {th }}$ value in the increasing list of the vector $\mathrm{G}_{1}$.

7. Repeat steps 5 and 6 to evaluate the failure thresholds $C_{3}, C_{4}, \ldots, C_{m}$ corresponding to the failure regions $\mathrm{F}_{3}, \mathrm{~F}_{4}, \ldots, \mathrm{F}_{\mathrm{m}}$. Notice that contrary to all other thresholds, the last threshold $\mathrm{C}_{\mathrm{m}}$ is negative. Thus, $\mathrm{C}_{\mathrm{m}}$ is set to zero and the conditional failure probability of the last level $\left[\mathrm{P}\left(\mathrm{F}_{\mathrm{m}} \mid \mathrm{F}_{\mathrm{m}}-1\right)\right]$ is calculated as:

$$
\mathrm{P}\left(\mathrm{F}_{\mathrm{m}} \mid \mathrm{F}_{\mathrm{m}-1}\right)=\frac{1}{\mathrm{~N}_{\mathrm{s}}} \sum_{\mathrm{k}=1}^{\mathrm{Ns}} \mathrm{I}_{\mathrm{F}_{\mathrm{m}}}\left(\mathrm{s}_{\mathrm{k}}\right)
$$

where $I_{F_{m}}=1$ if the performance function $G\left(s_{k}\right)$ is negative and $I_{F_{m}}=0$ otherwise.

8. Finally, the failure probability $\mathrm{P}(\mathrm{F})$ is evaluated according to Eq. (3).

\section{EXAMPLE PROBLEM}

In this section, the efficiency of the iSS is illustrated through an example problem. In this example, a probabilistic analysis at SLS of two neighboring strip footings resting on a soil with a spatially varying Young's modulus was performed. Each footing is subjected to a central vertical load $\mathrm{P}=1000 \mathrm{kN} / \mathrm{m}$. Due to the soil heterogeneity, the two footings exhibit a differential settlement $\delta$. This differential settlement is calculated as the absolute difference $\delta=\left|\delta_{1}-\delta_{2}\right|$ where $\delta_{1}$ and $\delta_{2}$ are the settlements (computed at the footing center) of the two footings. The differential settlement $\delta$ is used to represent the system response. The Young's modulus is modeled by a random field and it was assumed to follow a log-normal distribution. Its mean value and coefficient of variation are respectively $\mu_{\mathrm{E}}=60 \mathrm{MPa}$ and $\mathrm{COV}_{\mathrm{E}}=15 \%$. It was discretized using $\mathrm{K}-\mathrm{L}$ expansion. An exponential covariance function (Eq. 7) was used in this paper. Although an isotropic random field is often assumed in literature (e.g. Fenton and Griffiths 2002, 2005), the vertical autocorrelation length tends to be shorter than the horizontal one. A common ratio of about 1 to 10 for these autocorrelation lengths can be used (Baecher and Christian 
2003). Notice however that in this paper, different values of autocorrelation lengths were studied and analyzed in order to explore some interesting features related to the autocorrelation lengths. The performance function used to calculate the probability $\left(\mathrm{P}_{\mathrm{e}}\right)$ of exceeding a tolerable differential settlement is defined as follows:

$\mathrm{G}=\delta_{\max }-\delta$

where $\delta_{\max }$ is a prescribed tolerable differential settlement and $\delta$ is the computed differential settlement due to the soil heterogeneity. The deterministic model used to calculate the differential settlement $\delta$ is based on numerical simulations using FLAC. For this computation, two footings (each of width $b$ ) were considered in the analysis (Figure 3). The two footing centers are separated by a distance D. A non-uniform optimal mesh composed of 1290 zones was employed. Although this paper presents an SLS analysis, the soil behavior was modeled by a conventional elastic-perfectly plastic model based on Mohr-Coulomb failure criterion in order to take into account the possible plastification that may take place near the footing edges even under the service loads. The strip footings were modeled by a linear elastic model. They are connected to the soil via interface elements. The values of the different parameters of the soil, footings and interfaces are given in Table 1.

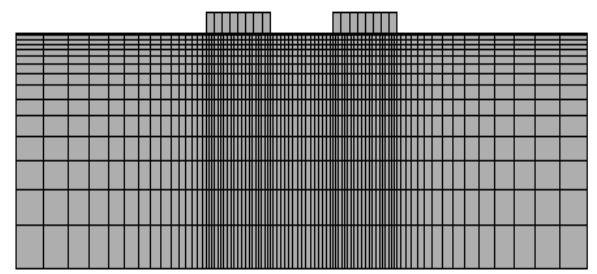

Figure 3. Soil domain and mesh used in the numerical simulations
Table 1. Shear Strength and Elastic Properties of Soil, Footing, and Interface

\begin{tabular}{cccc} 
Variable & Soil & Footing & Interface \\
\hline $\mathrm{c}$ & $20 \mathrm{kPa}$ & N/A & $20 \mathrm{kPa}$ \\
$\varphi$ & $30^{\circ}$ & N/A & $30^{\circ}$ \\
$\psi_{\mathrm{s}}=2 / 3 \varphi$ & $20^{\circ}$ & N/A & $20^{\circ}$ \\
$\mathrm{E}$ & $60 \mathrm{MPa}$ & $25 \mathrm{GPa}$ & N/A \\
$v$ & 0.3 & 0.4 & N/A \\
$\mathrm{K}_{\mathrm{n}}$ & $\mathrm{N} / \mathrm{A}$ & N/A & $1 \mathrm{GPa}$ \\
$\mathrm{K}_{\mathrm{s}}$ & $\mathrm{N} / \mathrm{A}$ & N/A & $1 \mathrm{GPa}$ \\
\hline
\end{tabular}

In order to calculate the differential settlement for a given random field realization, (i) the coordinates of the center of each element of the mesh were calculated; then, Eq. (6) was used to calculate the value of the Young's modulus at each element, (ii) geostatic stresses were applied to the soil, (iii) the obtained displacements were set to zero in order to obtain the footing displacement due to only the footings applied loads and finally, (iv) the service loads were applied to the footings and the vertical displacements at the footings centers due to these loads are calculated. The differential settlement is calculated as the absolute difference between the two footings displacements. It should be noticed that, for all the probabilistic analyses performed in this paper, a normal PDF was used as a target PDF (i.e. it was used to generate the $\underline{N}_{\underline{\underline{S}}}$ realizations of the first level). However, a uniform PDF was chosen as a proposal PDF (i.e. it was used to generate the $\underline{\mathrm{N}}_{\underline{s}}$ realizations of each one of the remaining levels). The intermediate failure probability $\mathrm{P}\left(\mathrm{F}_{\mathrm{i}}\right)$ was chosen equal to 0.1 . Also, the tolerable differential settlement $\delta_{\max }$ was assumed equal to $3.5 \times 10^{-3} \mathrm{~m}$. It should be mentioned here that $1_{\ln x}$ and $1_{\ln \mathrm{y}}$ were normalized with respect to the distance $\mathrm{D}$ between the centers of the two footings (i.e. $L_{\ln x}=l_{\ln x} / D$ and $L_{\ln y}=l_{\ln y} / D$ ). The numerical results have shown that this 
assumption is valid when the ratio $\mathrm{D} / \mathrm{b}$ is constant. Notice that all the probabilistic results presented in this paper correspond to a ratio of $\mathrm{D} / \mathrm{b}=2$. Finally, the number of terms of K-L expansion used in this paper is $\mathrm{M}=100$ terms except in the two following cases ( $\mathrm{L}_{\ln x}=\mathrm{L}_{\ln y}=0.25$ in case of an isotropic random field and, $\mathrm{L}_{\ln x} \leq 0.25$ and $\underline{L_{\ln }} \leqq 0.25$ in case of an anisotropic random field) where 500 terms were required.

\section{Probabilistic results}

This section presents the probabilistic results of the example problem described above. First, the number of realizations $\mathrm{N}_{\mathrm{s}}$ to be used in the different levels of iSS has to be selected. This number must be sufficient to provide accurate $\mathrm{P}_{\mathrm{e}}$ values. Different values of $\mathrm{N}_{\mathrm{s}}$ were considered. For each $\mathrm{N}_{\mathrm{s}}$ value the failure thresholds $\mathrm{C}_{1}, \mathrm{C}_{2}$, etc. were calculated and presented in Table 2 when the radius $\beta$ is equal to zero. This table shows that the value of the failure threshold decreases with the successive levels until reaching a negative value at the last level.

\begin{tabular}{|c|c|c|c|c|c|c|}
\hline \multirow{2}{*}{$\begin{array}{c}\text { Failure } \\
\text { threshold } \\
\mathrm{C}_{\mathrm{j}} \text { for each } \\
\text { level } \mathrm{j}\end{array}$} & \multicolumn{6}{|c|}{ Number of realizations at each level $\left(\mathrm{N}_{\mathrm{s}}\right)$} \\
\hline & 200 & 400 & 600 & 800 & 1000 & 1200 \\
\hline $\mathrm{C}_{1}$ & 0.00191 & 0.00199 & 0.00189 & 0.00204 & 0.00191 & 0.00195 \\
\hline $\mathrm{C}_{2}$ & 0.00103 & 0.00099 & 0.00096 & 0.00110 & 0.00102 & 0.00103 \\
\hline $\mathrm{C}_{3}$ & 0.00041 & 0.00032 & 0.00021 & 0.00037 & 0.00036 & 0.00034 \\
\hline $\mathrm{C}_{4}$ & -0.00009 & -0.00051 & -0.00036 & -0.00037 & -0.00039 & -0.00038 \\
\hline
\end{tabular}

For each $\mathrm{N}_{\mathrm{s}}$ value presented in Table 2, $\mathrm{P}_{\mathrm{e}}$ corresponding to each level $\mathrm{j}$ was calculated by iSS as follows:

$$
P\left(F_{j}\right)=P\left(F_{1}\right) \times P\left(F_{2} \mid F_{1}\right) \times \ldots \times P\left(F_{j} \mid F_{j-1}\right)
$$

These $\mathrm{P}_{\mathrm{e}}$ values were compared to those computed by the crude MCS methodology using a number $\mathrm{N}=30,000$ realizations (Figure 4). Notice that at a given level $\mathrm{j}$, the $\mathrm{P}_{\mathrm{e}}$ value is calculated by MCS methodology as follows:

$$
P\left(F_{j}\right)=\frac{1}{N} \sum_{k=1}^{N} I_{F}\left(G_{k}\right)
$$

in which, $\mathrm{G}_{\mathrm{k}}$ is the value of the performance function at the $\mathrm{k}^{\text {th }}$ realization and $\mathrm{I}_{\mathrm{F}}=1$ if $\mathrm{G}_{\mathrm{k}}<\mathrm{C}_{\mathrm{j}}$ and $\mathrm{I}_{\mathrm{F}}=0$ otherwise. The comparison has shown that for $\mathrm{N}_{\mathrm{s}}=1,000$ realizations, the $\mathrm{P}_{\mathrm{e}}$ value computed by iSS at the different levels is very close to that computed by the crude MCS methodology. Thus $\mathrm{N}_{\mathrm{s}}=1,000$ realizations will be used in all the probabilistic analyses performed in this paper. Notice that when $\mathrm{N}_{\mathrm{s}}=1,000$ realizations, the coefficient of variation of $\mathrm{P}_{\mathrm{e}}$ by iSS is $\mathrm{COV}_{\mathrm{Pe}}=31.5 \%$. However, $\mathrm{COV}_{\mathrm{Pe}}$ by MCS methodology using 30,000 realizations is equal to $31.3 \%$. Notice also that when $\beta=0$, four levels of SS were required to reach the limit state surface $\mathrm{G}=0$. This means that a total number of realization $\mathrm{N}_{\mathrm{t}}=1,000+(900 \times 3)=3,700$ realizations were required to calculate $\mathrm{P}_{\mathrm{e}}$. Thus, for the same accuracy, the number of realizations (and consequently, the computation time) is reduced by $87.7 \%$ with 
respect to MCS when $\beta=0$. (i.e. when the classical SS is used). This number can be again reduced by increasing $\beta$ (i.e. by using iSS). Table 3 shows that, when $\beta$ increases, the total number of realizations decreases. When $\beta=11.5$, only 2 levels are required. Thus, the total number of realizations is $\mathrm{N}_{t}=1000+900=1,900$ realizations.

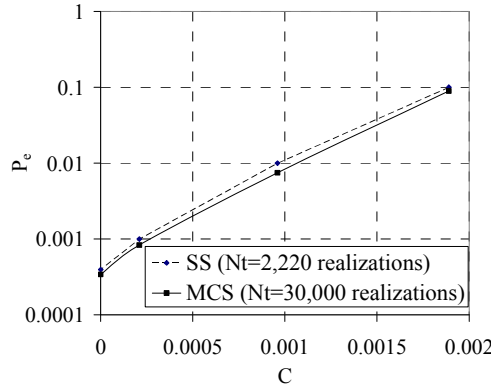

a. $\mathbf{N}_{\mathrm{s}}=600$ realizations per level

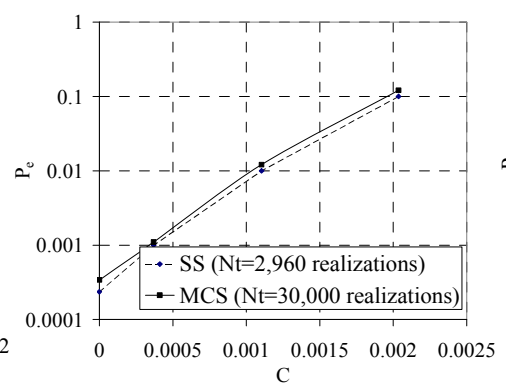

b. $\mathbf{N}_{\mathrm{s}}=\mathbf{8 0 0}$ realizations per level

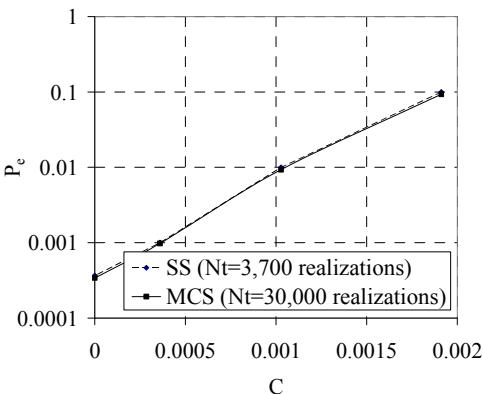

c. $\mathrm{N}_{\mathrm{s}}=1000$ realizations per level

Figure 4. Comparison between $P_{\mathrm{e}}$ computed by iSS and that computed by MCS methodology at each level of iSS $\left(\beta=0, L_{\ln x}=2.5\right.$ and $\left.L_{\ln y}=0.25\right)$.

As a conclusion, the number of realizations (and consequently, the computation time) required by SS approach could be reduced by $\underline{48.6 \%}$ by employing the iSS approach.

Table 3. Effect of the Radius of the Hypersphere on the Number of Realizations Required to Calculate $P_{e}\left(L_{\ln x}=2.5\right.$ and $\left.L_{\ln y}=0.25\right)$

\begin{tabular}{|c|c|c|c|c|c|}
\hline & \multirow{2}{*}{$\mathrm{MCS}$} & \multirow{2}{*}{$\begin{array}{c}\beta=0 \\
\text { (Classical SS })\end{array}$} & $\beta=10$ & $\beta=11$ & $\beta=11.5$ \\
\hline $\mathrm{P}_{\mathrm{e}}\left(\mathrm{x} 10^{-4}\right)$ & 3.40 & 3.65 & 3.58 & 3.36 & 3.45 \\
\hline Number of levels & - & 4 & 3 & 3 & 2 \\
\hline number of realizations & 30,000 & 3,700 & 2,800 & 2,800 & 1,900 \\
\hline$\underline{\text { computation time (minutes) }}$ & $\underline{210,000}$ & $\underline{25,900}$ & $\underline{19,600}$ & $\underline{19,600}$ & $\underline{13,300}$ \\
\hline
\end{tabular}

\section{Effect of the autocorrelation length on $P_{e}$ in the case of an isotropic random field}

Figure 5 shows the effect of the autocorrelation length on the $\mathrm{P}_{\mathrm{e}}$ value in the case of an isotropic random field. This figure indicates that $\mathrm{P}_{\mathrm{e}}$ presents a maximum value when $L_{\ln x}=L_{\ln } y=1$. This can be explained by the fact that when the autocorrelation lengths are very small, one obtains a highly heterogeneous soil in both the vertical and the horizontal directions with a great variety of high and small values of the Young's modulus beneath the footings. In this case, the soil under the footings contains a mixture of stiff and soft soil zones. Due to the high rigidity of the footings, their movements are resisted by the stiff soil zones. This leads to a small value of the footings displacements (i.e. to a small differential settlement) and thus, to a small value of $\mathrm{P}_{\mathrm{e}}$. On the other hand, when the autocorrelation lengths are large, the soil tends to be homogenous. This means that the differential settlement tends to be very small (close to zero) which leads to a very small value for $\mathrm{P}_{\mathrm{e}}$. For the intermediate values of the autocorrelation lengths corresponding to $\left(\mathrm{P}_{\mathrm{e}}\right)_{\max }$, there is a high probability that one footing rests on a stiff soil zone and the other on a relatively soft soil zone. This leads to a high differential settlement and thus to a high $\mathrm{P}_{\mathrm{e}}$ value. This configuration corresponds to the case where $\mathrm{L}_{\ln x}=\mathrm{L}_{\ln \mathrm{y}}=1$. 


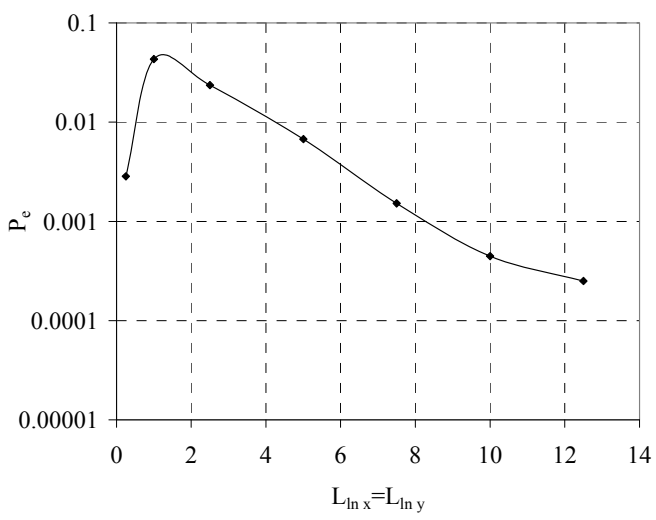

Figure 5. Effect of the autocorrelation lengths on $P_{e}$ (isotropic random field)

\section{Effect of the autocorrelation lengths on $P_{e}$ in the case of anisotropic random field}

Figures 6 shows the effect of $L_{\ln x}$ on $P_{e}$ when $L_{\ln y}=0.25$. This figure shows that $\mathrm{P}_{\mathrm{e}}$ presents a maximum value when $\mathrm{L}_{\ln \mathrm{x}}=1$. For the very small values of $\mathrm{L}_{\ln \mathrm{x}}$ compared to $\mathrm{L}_{\ln \mathrm{y}}$, one obtains a vertical multilayer composed of thin sub-layers where each sub-layer may have a high or a small value of the Young's modulus. The sub-layers with high values of the Young's modulus prevent the movements of both footings and thus lead to a small value of $\mathrm{P}_{\mathrm{e}}$. On the other hand, when $\mathrm{L}_{\ln } \mathrm{x}$ is very large compared to $\mathrm{L}_{l_{n}}{ }_{2}$ one obtains a horizontal multilayer (case of a onedimensional vertical random field) for which each sub-layer may have a high or a small value of the Young's modulus. This leads to the same displacement for both footings and thus to a very small value of $\mathrm{P}_{\mathrm{e}}$. Finally, when $\mathrm{L}_{\ln \mathrm{x}}$ is equal to 1 , the horizontally extended stiff layers become less extended and thus one obtains a greater differential settlement and consequently a greater value of $\mathrm{P}_{\mathrm{e}}$.

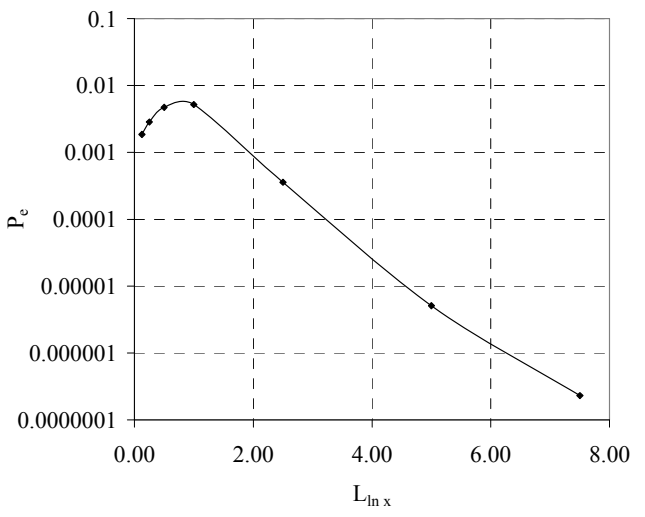

Figure 6. Effect of $L_{\ln x}$ on $P_{e}$ when $L_{\text {ln } y}=0.25$

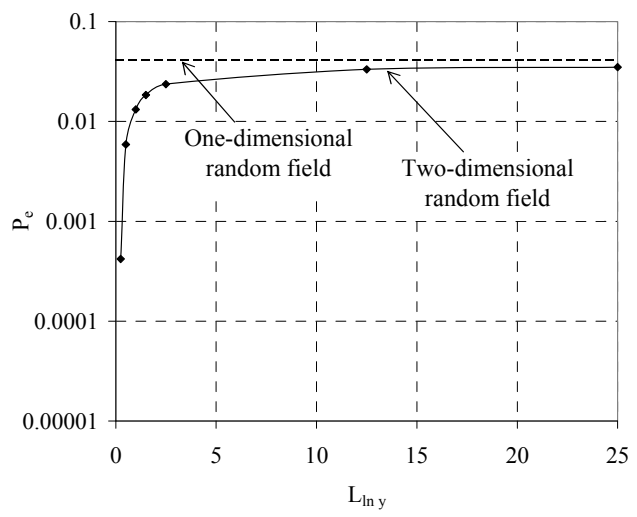

Figure 7. Effect of $L_{\ln y}$ on $P_{e}$ when $\mathrm{L}_{\ln \mathrm{x}}=\mathbf{2 . 5}$

The effect of $\mathrm{L}_{\ln y}$ is presented in Figure 7 when $\mathrm{L}_{\ln x}=2.5$. This figure shows that the $P_{e}$ value increases with the increase in $L_{\ln y}$. This can be explained as follows: when $\underline{L_{n}}$ y is very small, the two footings rest on a horizontal multilayer composed of thin sub-layers where each sub-layer may have a high or a small value of the Young's $\underline{\text { modulus. This means that } \delta_{1}} \underline{\text { and } \delta_{2}} \underline{a r e ~ a l m o s t ~ e q u a l . ~ T h u s, ~ t h e ~ d i f f e r e n t i a l ~ s e t t l e m e n t ~}_{2}$

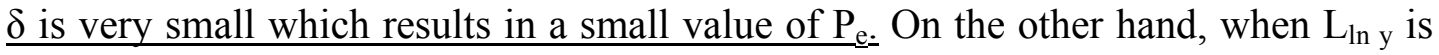
very large, the soil tends to the case of a one-dimensional horizontal random field. In 
this case, one obtains vertically extended stiff sub-layers adjacent to vertically extended soft sub-layers. For the chosen value of $\mathrm{L}_{\ln x}$, there is a high probability that one footing rests on a vertical stiff layer and the other one rests on a vertical soft layer which leads to a high differential settlement and thus to a great value of $\mathrm{P}_{\mathrm{e}}$.

\section{CONCLUSION}

This paper presents an efficient method to perform a probabilistic analysis of geotechnical structures that involve spatial variability. This method is an improvement of the classical subset simulation approach to calculate the small failure probabilities using a reduced number of realizations. It was illustrated through an example problem in which, a probabilistic analysis at SLS of two neighboring strip footings was performed. The footings rest on a soil with a spatially varying Young's modulus. The proposed procedure has significantly reduced the number of realizations required by the classical subset simulation approach to calculate the probability $\mathrm{P}_{\mathrm{e}}$ of exceeding a tolerable differential settlement. A parametric study to investigate the effect of the autocorrelations lengths on $\mathrm{P}_{\mathrm{e}}$ has shown that: (i) in case of an isotropic random field, $\mathrm{P}_{\mathrm{e}}$ presents a maximum value when the autocorrelation lengths are equal to the distance between the footings centers, (ii) in case of an anisotropic random field, for a given $L_{l n}$ y value, $P_{e}$ presents a maximum when $L_{l n}$ $x=D$. However, for a given value of $\mathrm{L}_{\ln x}, \mathrm{P}_{\mathrm{e}}$ increases with the increase in $\mathrm{L}_{\ln y}$ and then it attains an asymptote corresponding to the case of a one-dimensional random field.

\section{REFERENCES}

Ahmed, A., Soubra, A.-H., (2011). "Subset simulation and its application to a spatially random soil." GeoRisk 2011, June 26-28, Atlanta, Georgia:209-216.

Au, S.K., and Beck, J.L. (2001). "Estimation of small failure probabilities in high dimentions by subset simulation." Journal of Probabilistic Engineering Mechanics, 16: 263-277.

Baecher, G.B., and Christian, J.T. (2003). "Reliability and Statistics in Geotechnical Engineering." New York: Wiley.

Cho, S.E., and Park, H.C. (2010). "Effect of spatial variability of cross-correlated soil properties on bearing capacity of strip footing." International Journal for Numerical and Analytical Methods in Geomechanics, 34: 1-26.

Defaux, G., Meister, E., and Pendola, M. (2010). "Mécanique probabiliste et intégrité des cuves des réacteurs nucléaires." JFMS'10, Toulouse, France: 23 pages

Fenton, G.A., and Griffiths, D.V. (2002). "Probabilistic foundation settlement on a spatially random soil." Journal of Geotechnical and Geoenvironmental Engineering, ASCE, 128(5): 381-390.

Fenton, G.A., and Griffiths, D.V. (2005). "Three-dimensional probabilistic foundation settlement." Journal of Geotechnical and Geoenvironmental Engineering, ASCE, 131(2): 232-239.

Spanos, P.D., and Ghanem, R. (1989). "Stochastic Finite Element Expansion for Random Media." Journal of Engineering Mechanics, ASCE, 115(5): 1035-1053. 